$\mathrm{Cl}$ oni ng and expressi on of vacuol ar prot on- pumpi ng ATPase subuni ts i $n$ the fol I i cul ar epi thel i um of the bul I frog endol ymphat i c sac

\begin{tabular}{|l|l|}
\hline 著者 & $\begin{array}{l}\text { Yaj i ma Shi nya, Kubota Nakot o, Nakakur a } \\
\text { Takashi, Hasegawa Takahi ro, Kat agi r i Nobut o, } \\
\text { Tomur a Hi deaki, Sasayana Yui chi, Suzuki } \\
\text { Nasakazu, Tanaka Shi geyasu }\end{array}$ \\
\hline $\begin{array}{l}\text { j our nal or } \\
\text { publ i cat i on ti tl e }\end{array}$ & Zool ogi cal Sci ence \\
\hline vol une & 24 \\
\hline nunber & 2 \\
\hline page r ange & $147-157$ \\
\hline year & $2007-01$ - 01 \\
\hline URL & ht t p: //hdl . handl e. net /2297/9843 \\
\hline
\end{tabular}




\title{
Cloning and Expression of Vacuolar Proton-Pumping ATPase Subunits in the Follicular Epithelium of the Bullfrog Endolymphatic Sac
}

\author{
Shinya Yajima ${ }^{1}$, Makoto Kubota ${ }^{1}$, Takashi Nakakura', Takahiro Hasegawa', \\ Nobuto Katagiri ${ }^{1}$, Hideaki Tomura ${ }^{2}$, Yuichi Sasayama ${ }^{3}$, \\ Masakazu Suzuki ${ }^{1}$ and Shigeyasu Tanaka ${ }^{*}$ \\ ${ }^{1}$ Department of Biology, Faculty of Science, Shizuoka University, Shizuoka 422-8529, Japan \\ ${ }^{2}$ Institute for Molecular and Cellular Regulation, Gunma University, \\ Maebashi 371-8512, Japan \\ ${ }^{3}$ Divison of Biodiversity, Noto Marine Laboratory, Institute of Natural \\ and Environmental Technology, Kanazawa University, \\ Kanazawa 920-1192, Japan
}

\begin{abstract}
In an investigation aimed at clarifying the mechanism of crystal dissolution of the calcium carbonate lattice in otoconia (the mineral particles embedded in the otolithic membrane) of the endolymphatic sac (ELS) of the bullfrog, CDNAs encoding the A- and E-subunits of bullfrog vacuolar protonpumping ATPase (V-ATPase) were cloned and sequenced. The CDNA of the A-subunit consisted of an 11-bp 5'-untranslated region (UTR), a 1,854-bp open reading frame (ORF) encoding a protein comprising 617 amino acids with a calculated molecular mass of $68,168 \mathrm{Da}$, and a 248-bp 3'-UTR followed by a poly(A) tail. The cDNA of the E-subunit consisted of a 72-bp 5'-UTR, a 681-bp ORF encoding a protein of 226 amino acids with a calculated molecular mass of $26,020 \mathrm{Da}$, and a 799bp 3'-UTR followed by a poly(A) tail. Western blot and immunofluorescence analyses using specific anti-peptide antisera against the V-ATPase A- and E-subunits revealed that these subunits were present in the ELS, urinary bladder, skin, testes, and kidneys. In the ELS, positive cells were scattered in the follicular epithelium which, as revealed by electron microscopy, corresponds to the location of mitochondria-rich cells. These findings suggest that V-ATPase, including the A- and Esubunits, exists in mitochondria-rich cells of the ELS, which might be involved in dissolution of the calcium carbonate crystals in the lumen of the ELS.
\end{abstract}

Key words: Endolymphatic sac, vacuolar $\mathrm{H}^{+}$-pumping ATPase, cDNA cloning, anti-peptide antibody, immunocytochemistry, Rana catesbeiana

\section{INTRODUCTION}

The amphibian endolymphatic sac (ELS) not only enlarges to form extensions around the brain but also extends caudally along the vertebral canal and protrudes between the vertebrate, where it is referred to as the paravertebral lime sac (PVLS). The lumen of these sacs contains many tiny crystals composed of calcium carbonate. Yaoi et al. (2001) determined that otoconin-22 protein is present in the ELS surrounding the pituitary gland and the PVLS in the bullfrog. Otoconin-22 is believed to be important in creating conditions that favor nucleation and, subsequently, in controlling the crystal growth of the calcium carbonate lattice in otoconia (mineral particles embedded in the otolithic membrane). A subsequent study by these researchers (Yaoi et al., 2003) resulted in the cloning and sequenc-

\footnotetext{
* Corresponding author. Phone: +81-54-238-4783;

Fax : +81-54-238-0986;

E-mail: sbstana@ipc.shizuoka.ac.jp
}

ing of a cDNA encoding bullfrog otoconin-22 and provided evidence that calcitonin regulates the expression of otoconin-22 mRNA in the ELS, thereby stimulating the formation of calcium crystals in the lumen of the ELS. These results led to the conclusion that the amphibian ELS functions as a reservoir for calcium, although the mechanism by which these crystals are dissolved remained unclear. One hypothesis is that cells bearing vacuolar proton-pumping ATPase (vacuolar $\mathrm{H}^{+}$-ATPase or V-ATPase) are present in the follicular epithelium of the ELS and release protons into the lumen, thereby generating an acidic $\mathrm{pH}$ environment that subsequently results in dissolution of the crystals.

V-ATPase is an ATP-dependent proton pump responsible for translocating protons into intracellular organelles, including the endosomes, trans-Golgi network, lysosomes, and synaptic vesicles of eukaryotic cells (Forgac, 1999; Futai et al., 2000; Nelson and Harvey, 1999; Wagner et al., 2004). In addition, V-ATPase is highly expressed on the plasma membrane of specialized cells, such as mammalian renal intercalated cells, osteoclasts, teleost chloride cells, 
and amphibian skin and urinary bladder mitochondria-rich (MR) cells, that are involved in the active transport of protons into extracellular compartments and in the $\mathrm{pH}$ regulation of these compartments (Brown and Breton, 1996; Wieczorek et al., 1999). The V-ATPase molecule comprises two main domains: a cytosolic domain $\left(\mathrm{V}_{1}\right)$ and a transmembrane domain $\left(\mathrm{V}_{0}\right)$ (Wagner et al., 2004). The $\mathrm{V}_{1}$ domain (molecular mass of $\sim 640 \mathrm{kDa}$ ) is responsible for the hydrolysis of ATP, whereas the $240-k D a V_{0}$ domain is responsible for proton translocation across the membrane. The $V_{1}$ domain consists of eight different subunits $(A-H)$. The $V_{0}$ domain is formed by five different subunits, namely, subunits a and d and proteolipids c, c', and c" (Nishi and Forgac, 2002).

In the investigation reported here, we cloned and sequenced cDNAs encoding the $A$ - and E-subunits of bullfrog V-ATPase. Using homologous peptide antibodies specific for these subunits, we also examined the immunolocalization of the V-ATPase subunits in several tissues, including the ELS of the bullfrogs.

\section{MATERIALS AND METHODS}

\begin{abstract}
Animals
Adult bullfrogs (Rana catesbeiana) were purchased from Ouchi (Misato, Japan). They were acclimated under normal laboratory conditions for at least one week prior to being sacrificed. The ELS including PVLS was removed immediately following decapitation and processed for immunohistochemical and Western blot analyses, and electron microscopy. Several other tissues - the urinary bladder, ventral skin, kidney, and testis - were also prepared for Western blot analysis and immunohistochemistry. All animal experiments were in compliance with the Guide for Care and Use of Laboratory Animals of Shizuoka University.
\end{abstract}

\section{Cloning of bullfrog A- and E-subunits of V-ATPase}

Using a bullfrog PVLS cDNA library established in our previous study (Yaoi et al., 2003), we cloned cDNAs encoding the A- and Esubunits of V-ATPase. Partial cDNA fragments of bullfrog A- and Esubunits of V-ATPase were obtained by designing degenerate primers based on amino acid sequences from other species. The following primers (5' to $3^{\prime}$ ) were obtained commercially (Life Technologies, Japan): A-subunit primer 1 [AACAG(C/T)GA(C/T)GT(A/G/C) ATCAT(C/T)TA] and A-subunit primer 2 [TTGCTGTA(A/G)CTGAT (C/G)AGCCA(A/G)TT]; E-subunit primer 1 [CA(C/T)ATGATGGC(A/ $\mathrm{G} / \mathrm{C} / \mathrm{T}) \mathrm{TT}(\mathrm{C} / \mathrm{T}) \mathrm{AT}(\mathrm{A} / \mathrm{C} / \mathrm{T}) \mathrm{GA}]$ and $\mathrm{E}$-subunit primer primer $2[\mathrm{TG}(\mathrm{A} /$ G)TA(A/G/C/T)CG(A/G/C/T)GT(A/G/C/T)GT(A/G)TC(C/T)TT].

We performed polymerase chain reaction (PCR) analyses using cDNA prepared from the bullfrog PVLS cDNA library in $25-\mu \mathrm{l}$ volumes of Ex-taq buffer containing $0.2 \mathrm{mM}$ each dNTP and 50 pmol of each of primers 1 and 2 with $0.5 \mathrm{U}$ of Ex-taq polymerase (Takara, Kyoto, Japan), as described by Yaoi et al. (2003). The PCR amplification procedure consisted of an initial denaturation step at $95^{\circ} \mathrm{C}$ for $5 \mathrm{~min}$ followed by denaturation $\left(94^{\circ} \mathrm{C}, 90 \mathrm{sec}\right)$, annealing $\left(50^{\circ} \mathrm{C}, 90 \mathrm{sec}\right)$, and extension $\left(72^{\circ} \mathrm{C}, 150 \mathrm{sec}\right)$ for 30 cycles in a thermal cycler (ASTEC, Fukuoka, Japan). Amplified fragments were cloned into pGEM-3Z vector (Promega, Madison, Wis.).

\section{Screening of a bullfrog PVLS cDNA library}

We synthesized DNA probes from the PCR products using a Digoxigenin (DIG)-High Prime Kit (Roche Molecular Biochemicals, Meylan, France) and used these to screen the cDNA library of the bullfrog PVLS following the manufacturer's instructions. The membrane was hybridized with the DIG-labeled cDNA probes at $68^{\circ} \mathrm{C}$ overnight and washed twice in $1 \mathrm{X}$ saline-sodium citrate (SSC)/
$0.1 \%$ sodium dodecyl sulfate (SDS) for $1 \mathrm{~h}$ at $50^{\circ} \mathrm{C}$. After blocking, the membrane was incubated with alkaline phosphatase-conjugated sheep anti-DIG Fab antibody (Roche), reacted with $25 \mathrm{mM}$ CSPD [disodium 3-(4-methoxyspiro\{1, 2-dioxetane-3, 2'-(5'-chloro)tricyclo(3.3.1.13.7)decan\}-4-yl)phenyl phosphate] chemiluminescent substrate (Tropix; PE Applied Biosystems, Foster City, Calif.) and then visualized on Hyperfilm-ECL (Amersham Pharmacia Biotech, Buckinghamshire, UK).

\section{DNA sequence analysis}

The cDNAs were sequenced using an ABI PRISM BigDye Terminator Cycle Sequencing Kit (PE Applied Biosystems). The sequencing reactions were analyzed by an Applied Biosystems DNA sequencer (model 377; PE Applied Biosystems).

\section{Antibodies}

An oligopeptide comprising amino acids 366-381 (ST-170: AEMPADSGYPAYLGAR) of the V-ATPase A-subunit and an oligopeptide corresponding to the C-terminal amino acids 213-226 (ST-173: VALFGANANRKFLD) of the E-subunit, with an amino-terminal cysteine residue, were synthesized with a PE Applied Biosystems Model 433A synthesizer. The crude peptides were purified by reverse-phase high-performance liquid chromatography (HPLC) with a $0-60 \%$ linear gradient of $\mathrm{CH}_{3} \mathrm{CN}$ in $0.1 \%$ trifluoroacetic acid. The purification of the peptides was confirmed by measuring their molecular mass by mass spectrometry (Sciex API 150EX; Applied Biosystems). Antisera were raised in rabbits immunized with the ST-170 or ST-173 peptides coupled to keyhole limpet hemocyanin $(\mathrm{KLH})$ with $\mathrm{m}$-maleimidobenzoyl- $N$-hydroxysuccinimide ester (MBS; Pierce, Rockford, III.) as described previously (Tanaka and Kurosumi, 1992). The antibody against bullfrog otoconin-22 protein, prepared and characterized as described by Yaoi et al. (2001), was a guinea pig antiserum against a synthetic peptide corresponding to $\mathrm{N}$-terminal amino acids 1-13 (ST-135: TPAQFDEMIKVTT) of bullfrog otoconin-22.

\section{Western blot analysis}

To remove the calcium carbonate from the ELS, we treated the latter with $10 \%$ ethyenediamine-N,N,N,N'-tetraacetatic acid (EDTA) in water at $4^{\circ} \mathrm{C}$ for 3 days according to the method of Pote et al. (1993). These samples were homogenized in cell lysis buffer (50 $\mathrm{mM}$ Tris- $\mathrm{HCl}, \mathrm{pH} 8.0,0.15 \mathrm{M} \mathrm{NaCl}, 1 \%$ Triton $\mathrm{X}-100,0.1 \mathrm{mg} / \mathrm{ml}$ PMSF, $1 \mu \mathrm{g} / \mathrm{ml}$ aprotinin) and centrifuged in a microcentrifuge for 10 $\min$ to remove insoluble material. Protein concentrations were determined with a BCA Protein Assay Kit (Pierce). The supernatant protein $(10 \mu \mathrm{g})$ was denatured at $70^{\circ} \mathrm{C}$ for $10 \mathrm{~min}$ in denaturation buffer (2\% SDS, $25 \mathrm{mM}$ Tris- $\mathrm{HCl}$, pH 7.5, 25\% glycerol, $0.005 \%$ bromophenol blue) and then subjected to electrophoresis on a $12 \%$ polyacrylamide gel. Proteins were transferred to an Immobilon-P membrane (Millipore, Tokyo, Japan) and reacted sequentially with rabbit anti-A-subunit (ST-170) or anti-E-subunit serum (ST-173), biotinylated goat anti-rabbit IgG (DAKO Japan, Kyoto, Japan), and streptavidin-conjugated horseradish peroxidase (DAKO Japan). The reaction products on the membrane were visualized using an $\mathrm{ECL}$ Western Blot Detection Kit (Amersham Pharmacia Biotech). To check the specificities of the immunoreactions, we performed absorption tests by preincubating the anti-A-subunit (ST-170) or anti-E-subunit (ST-173) with the respective antigen peptides $(10 \mu \mathrm{g} /$ $\mathrm{ml})$.

\section{Immunofluorescence}

The ELS, urinary bladder, ventral skin, kidneys, and testes were fixed overnight at $4^{\circ} \mathrm{C}$ in periodate-lysine-paraformaldehyde (PLP) fixative, dehydrated, and embedded in Paraplast. Special attention was given to the ELS, which was treated with $10 \%$ EDTA in water at $4^{\circ} \mathrm{C}$ for 3 days to demineralize the calcium carbonate crystals following fixation. Thin $(4-\mu \mathrm{m})$ sections were cut and 
$-4$

1 atggatttttctaAactgccaagaAtcagcgatgaggahaggagagcatgctgggatttgtccatgggetgtctggaccagtggtgacg 90

$\begin{array}{llllllllllllllllllllllllllllllllll} & M & D & F & S & K & L & P & R & I & S & D & E & E & E & E & S & M & L & G & F & V & H & G & V & S & G & P & V & V & T & 30\end{array}$

91 GCAGCGCAGATGTCGGGGGCCGCCATGTATGAGTTGGTTCGAGTTGGTCATTCAGAACTTGTGGGTGAGATCATCCGGCTGGAGGGAGAC 180 $\begin{array}{llllllllllllllllllllllllllllllllllllll} & 31 & A & A & O & M & S & G & A & A & M & Y & E & L & V & R & V & G & H & S & E & L & V & G & E & I & \text { I } & R & L & E & G & D & 60\end{array}$

181 TTGGCCACCATTCAAGTGTATGAAGAGACCTCTGGCGTGTCGGTGGGAGATCCGGTGCTGCGGACTGGGAGCCTCTCTCGGTAGAGTTG 270 $\begin{array}{lllllllllllllllllllllllllllllllll}61 & L & A & T & I & O & V & Y & E & E & T & S & G & V & S & V & G & D & P & V & L & R & T & G & K & P & L & S & V & E & L & 90\end{array}$

271 GGCCCGGGCATTATGGGAAACATTTTTGATGGGATCCAGCGTCCTTTAAAAGATATTTCAGACATGACAAAAAGTATTTACATCCCTCGG 360

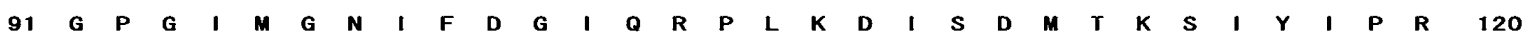
361 GGTATTAATGTGACCGCTCTGTCCAGAGATATCAAGTGGGAGTITATTCCAGACAAAAACATCAGGGCAGGTAGCCATTTGACTGGAGGG 450 $\begin{array}{lllllllllllllllllllllllllllllllllll} & 121 & G & \text { I } & \text { N } & \text { V } & \text { T } & \text { A } & \text { L } & \text { S } & \text { R } & \text { D } & \text { I } & \text { K } & \text { W } & \text { E } & \text { F } & \text { I } & \text { P } & \text { D } & \text { K } & \text { N } & \text { I } & \text { R } & \text { A } & \text { G } & \text { S } & \text { H } & \text { L } & \text { T } & G & G & 150\end{array}$

451 GATATCTACGgGAGTGTCACAGAGAATTCTCTCATCAAACACAAAATCATGGTACCCCCCCGAAGCCGTGGAACTGTCACCTATGTCGCT 540 $\begin{array}{llllllllllllllllllllllllllllllllll}151 & D & \text { I } & Y & G & S & V & T & E & N & S & L & \text { I } & K & \text { H } & K & \text { I } & M & V & P & P & R & S & R & G & T & V & T & Y & V & A & 180\end{array}$ 541 CCCCCTGGGAACTATGACATTTCAGATGTGGTTCTAGAATTGGACTTCGAAGGCATCAAAGAAAAGCTGACCATGGTACAGGTGTGGCCA 630

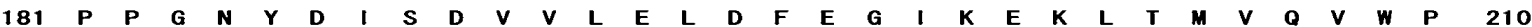

631 GTGCGGCAGATTCGACCAACCGCAGAGAAGCTTCGAGCCAACTACCCACTGCTGACTGGAGAGAGAGTCTTGGACGCCCTTTTCCCATGT 720 $\begin{array}{llllllllllllllllllllllllllllllllll}211 & V & R & 0 & \text { I } & R & P & T & A & E & K & L & P & A & N & Y & P & L & L & T & G & 0 & R & V & L & D & A & L & F & P & C & 240\end{array}$ 721 GTCCAAGGTGGAACCACAGCAATCCCTGGTGCCTTCGGCTGTGGGAAGACCGTGATCTCTCAGGCTTTATCCAAGTTCTCCAATAGTGAT 810

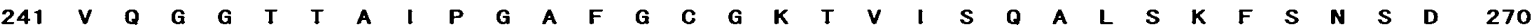

811 ATCATTGTATACGTGGGCTGTGGAGAGAGAGgTAAGGAGATGTCAGAGGTGCTGAGAGACTTCCCAGAGCTTACCATGGAGGTTAATGGG 900 $\begin{array}{llllllllllllllllllllllllllllllllll}271 & 1 & \text { I } & V & Y & V & G & C & G & E & R & G & N & E & M & S & E & V & L & R & D & F & P & E & L & T & M & E & V & N & G & 300\end{array}$ 901 AAAACTGAGACAATCATGAAAAGGACAACTCTGGTGGCAAACACATCCAACATGCCGGTGGGAGCTAGAGAGgCCTCAATCTACACAGGA 990

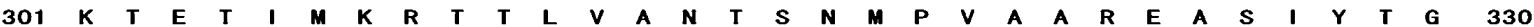
991 ATCACCCTGTCTGAATATTTCGGAGATATGgGTTACAACGTCAGTATGATGgGGGACTCCACTTCACGATGgGCTGAGgGGCTGAGAGAA 1080

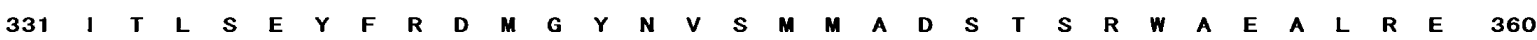
1081 ATCTCTGGTCGTTIGgCAgAAATGCCAGCTGATAGCGgTTACCCAGGGTACCTTGGCGCTCGATTGGCCTCCTTCTATGAGAGgGCAGgA 1170 $\begin{array}{lllllllllllllllllllllllllllllllll}361 & \text { I } & S & G & R & L & A & E & M & P & A & D & S & G & Y & P & A & Y & L & G & A & R & L & A & S & F & Y & E & R & A & G & 390\end{array}$

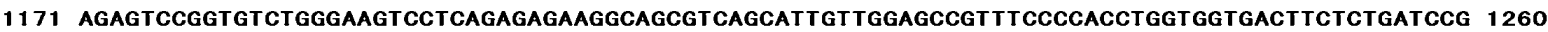
$\begin{array}{llllllllllllllllllllllllllllllll}391 & R & V & R & C & L & G & S & P & O & R & E & G & S & V & S & I & V & G & A & V & S & P & P & G & G & D & F & S & D & P & 420\end{array}$

1261 GTCACATCAGCCACTCTGgGTATTGTGCAGgTGTTCTGGgGACTAGAGAAGAAATTAGCCCAAAGGAAACATTTTCCATCTGTGAACTGG 1350

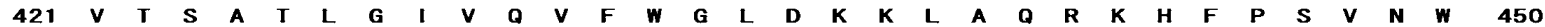

1351 CTCATCAGTTACAGCAAGTAGATGAggGCACTgGaTgAATATTATGAGAAGAACTTTGCTGAACTGgTACCACTTCGAACCAAAGCCAAA 1440 $\begin{array}{llllllllllllllllllllllllllllllll}451 & L & I & S & Y & S & K & Y & M & R & A & L & D & E & Y & Y & E & K & N & F & A & E & L & V & P & L & R & T & K & A & K & 480\end{array}$

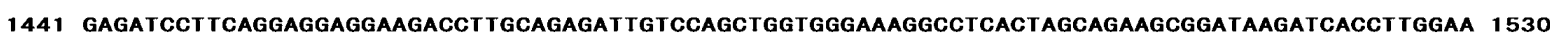

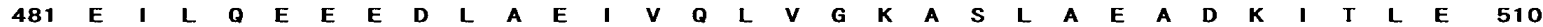

1531 GITGCTAAACTGATAAAGGTGATITCCTCCAGCAGAATGGCTACTCGGCCTATGACAGATTCTGICCITTITACAAGACGGIGgGAATG 1620 $\begin{array}{llllllllllllllllllllllllllllllllll}511 & V & A & K & \text { L } & \text { I } & \text { K } & \text { D } & \text { D } & \text { F } & \text { L } & \text { O } & \text { O } & \text { N } & \text { G } & \text { Y } & \text { S } & \text { A } & \text { Y } & \text { D } & \text { R } & \text { F } & \text { C } & \text { P } & \text { F } & \text { Y } & \text { K } & \text { T } & \text { V } & G & M & 540\end{array}$

1621 CTGGAGAAGATGATCGCCTICTATGACATGGCGCGACATGCGGTGGAAGCCACGGCTCAGGGAGAAAATAAAATAACCTGGGCAATAATC 1710 $\begin{array}{lllllllllllllllllllllllllllllllll}541 & \text { L } & \text { O } & \text { N } & \text { M } & \text { I } & \text { A } & \text { F } & \text { Y } & \text { D } & \text { M } & \text { A } & \text { R } & \text { H } & \text { A } & \text { V } & \text { E } & \text { A } & \text { T } & \text { A } & \text { O } & \text { A } & \text { E } & \text { N } & \text { K } & \text { I } & \text { I } & \text { W } & \text { A } & \text { I } & \text { I } & 570\end{array}$

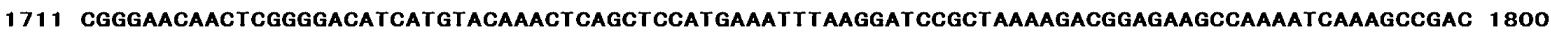

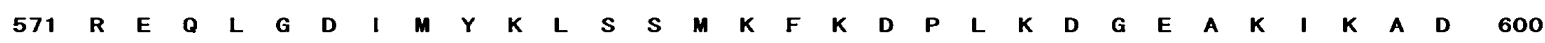

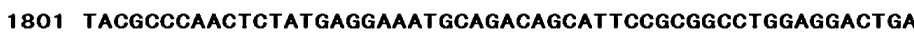
1854

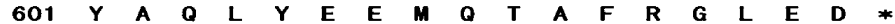

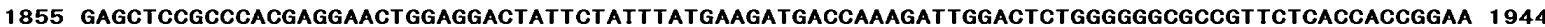

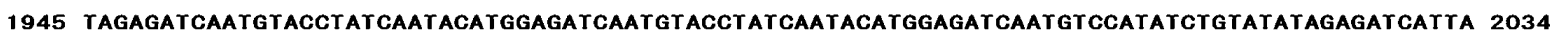

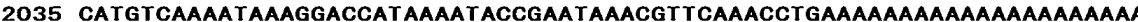
2103

Fig. 1. Nucleotide and deduced amino acid sequences of the bullfrog A-subunit of V-ATPase. The predicted amino acid is shown below the nucleotide sequence. The asterisk indicates the termination codon. 
mounted on gelatin-coated slides. The deparaffinized sections were rinsed with distilled water and PBS. For single labeling of the A- and E-subunit proteins, immunofluorescence staining was performed essentially as described by Tanaka et al. (1997). The sections were sequentially incubated with $1 \%$ bovine serum albumin-PBS, rabbit anti-A-subunit or E-subunit serum (1:4000), and indocarbocyanine (Cy3)-labeled donkey anti-rabbit IgG (Jackson). For nuclear coun- terstaining, 4', 6-diamidino-2-phenylindole (DAPI) was included in the secondary antibody solution. Several sections of the ELS were double-stained with guinea pig anti-otoconin-22 antibody and either rabbit anti-V-ATPase E-subunit or anti-V-ATPase A-subunit antibody, followed by Alexa 488-labeled goat anti-guinea pig IgG (Molecular Probes, Eugene, Ore.) and Cy3-labeled donkey anti-rabbit IgG (Jackson). As a last step, the sections were washed with

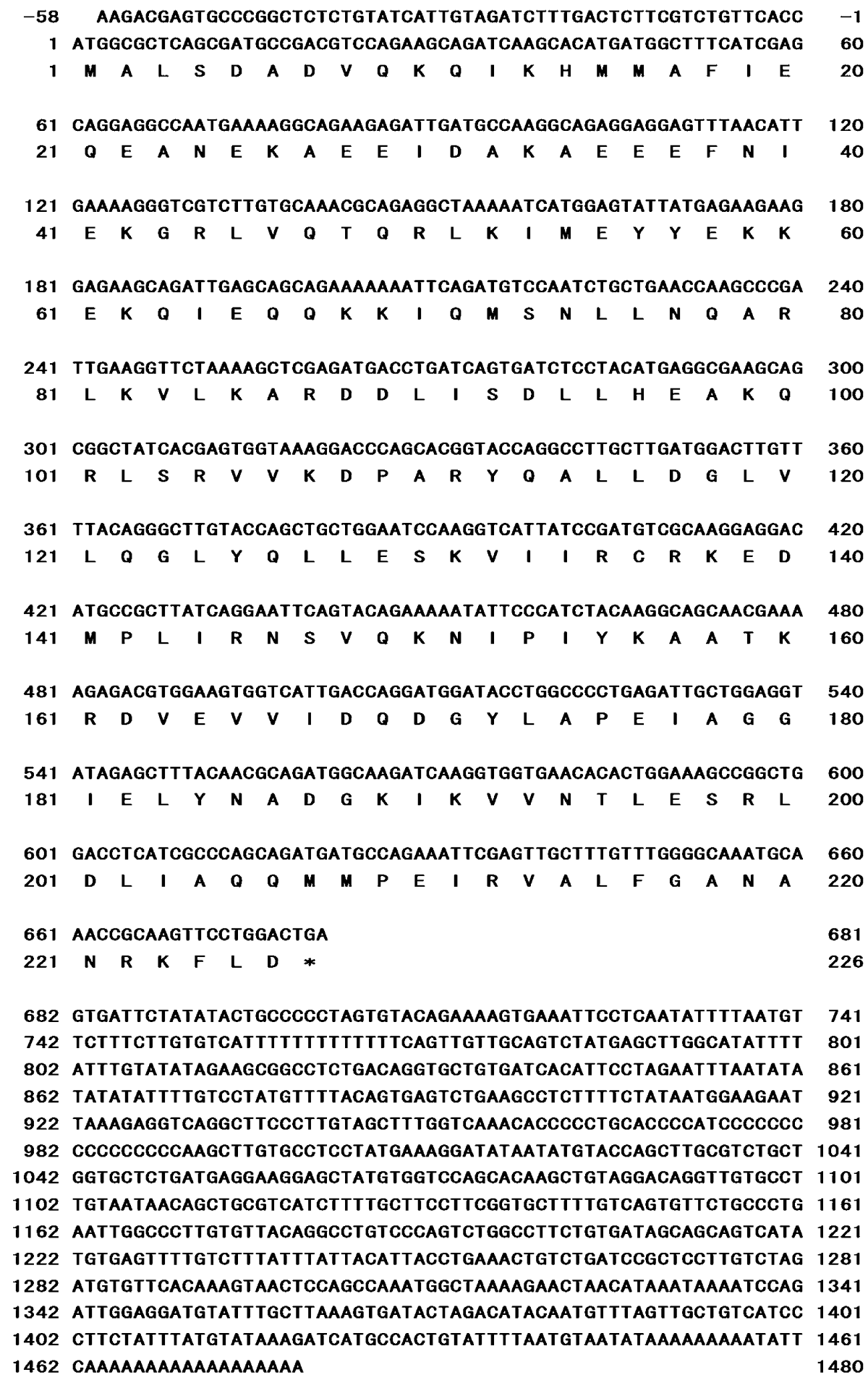

Fig. 2. Nucleotide and deduced amino acid sequences of the bullfrog E-subunit of V-ATPase. The predicted amino acid is shown below the nucleotide sequence. The asterisk indicates the termination codon. 
PBS and mounted in PermaFluor (Immunon, Pittsburgh, Pa.). To check the specificity of the immunostaining, we performed an absorption test by preincubating anti-A-subunit or E-subunit with ST-170 or ST-173 peptide $(10 \mu \mathrm{g} / \mathrm{ml})$. Specimens were examined with an Olympus BX50 microscope equipped with a BX-epifluorescence attachment (Olympus Optical, Tokyo, Japan).

\section{Electron microscopy and immunoelectron microscopy}

For standard electron microscopy, ELS tissues were fixed with a mixture of $2 \%$ glutaraldehyde and $2 \%$ parformaldehyde in $0.1 \mathrm{M}$ cacodylate buffer, $\mathrm{pH} 7.4$, at $4^{\circ} \mathrm{C}$ for $2 \mathrm{hr}$ and then decalcified by the procedure described above. They were postfixed for $1.5 \mathrm{hr}$ at $4^{\circ} \mathrm{C}$ in $1 \%$ osmium tetroxide in the same buffer. Following three washes with the above buffer, the tissue samples were dehydrated

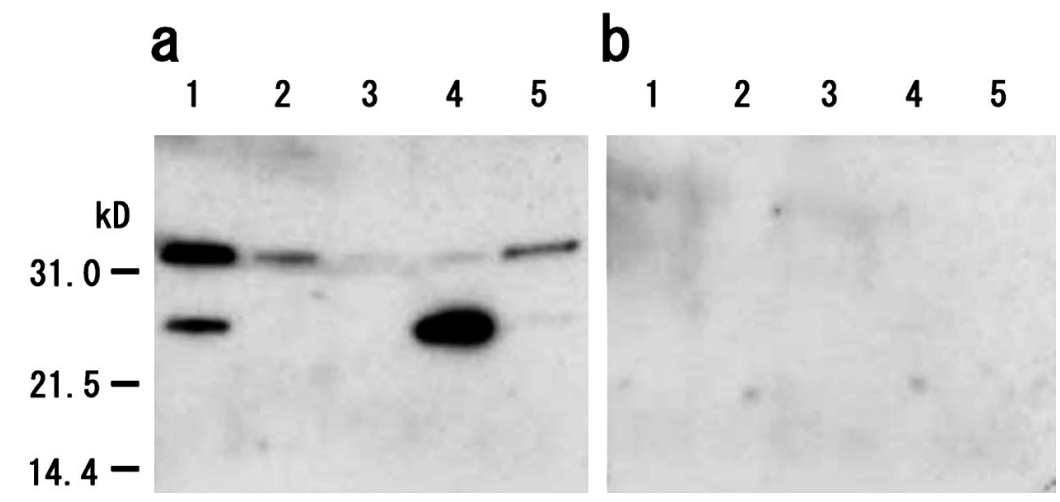

Fig. 3. Characterization of the bullfrog anti-V-ATPase E-subunit by Western blot analysis. (a) Immunoreactive bands are seen at $32.8 \mathrm{kDa}$ and at $25.4 \mathrm{kDa}$ in extracts of the endolymphatic sacs (lane 1) and testes (lane 4), and at $32.8 \mathrm{kDa}$ in the extracts of urinary bladder (lane 2), ventral skin (lane 3), and kidneys (lane 5). Note the differential expression of the bands in each of the samples. (b) Membrane was immunostained with antiserum preabsorbed with the antigen $(10 \mu \mathrm{g} / \mathrm{ml})$. Immunoreactive bands were completely eliminated.
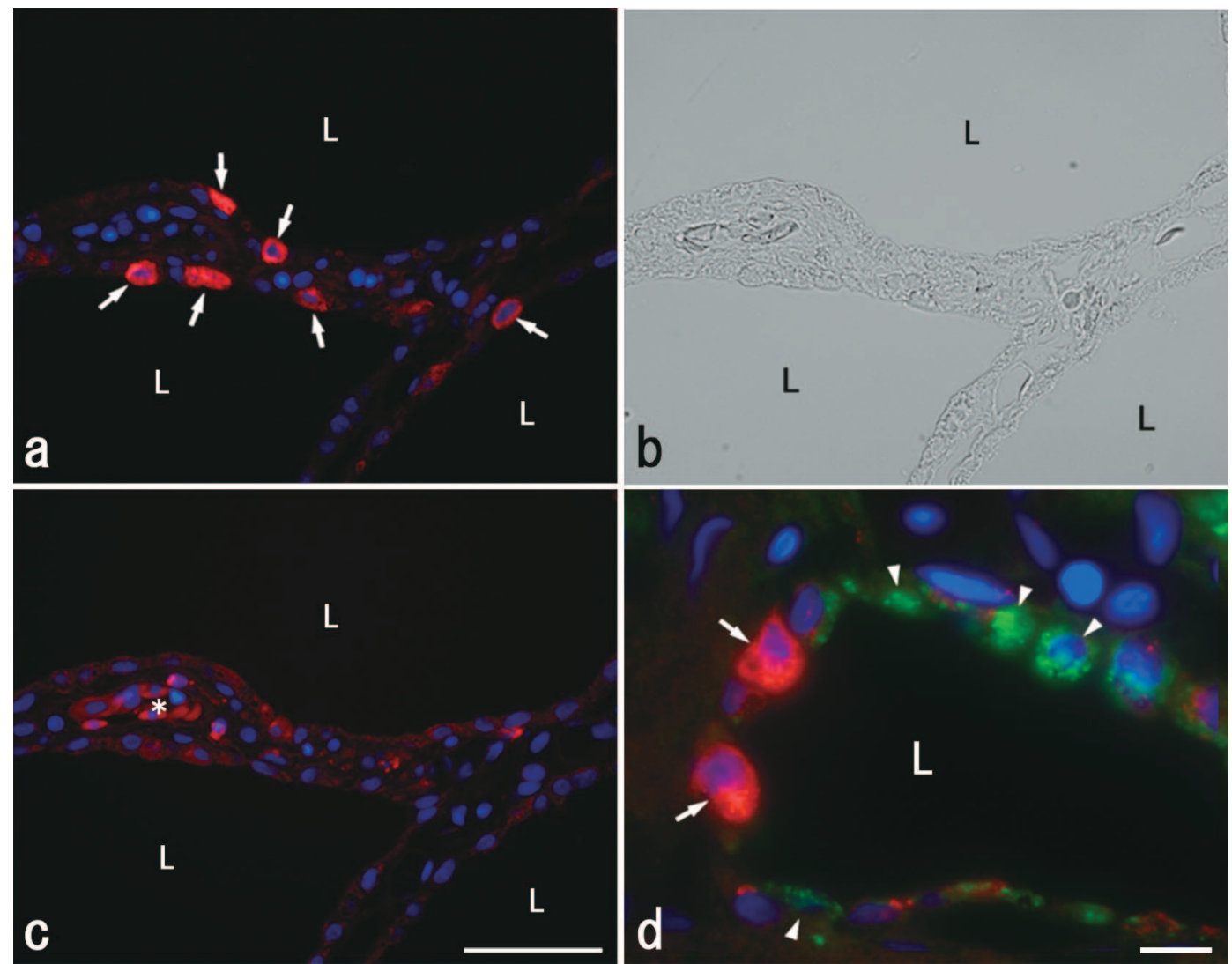

Fig. 4. Immunofluorescence localization of the V-ATPase E-subunit and otoconin-22 in the endolymphatic sac. A fluorescence image for VATPase (a) and the corresponding Nomarski differential-interference constrast image (b) are shown. The labels (red; arrows) are clearly visible in the cytoplasm of special cells in the follicular epithelium. (c) No labeling is evident in any of the cells of the endolymphatic sac when the antiV-ATPase E-subunit is preabsorbed with the corresponding antigen peptide. (d) In this double-labeling image, V-ATPase-expressing cells (red; arrows) are observed among otoconin-22-producing cells (green; arrowheads). Nuclei are counterstained with DAPI (blue). Asterisks, red blood cells; L, lumen. Bars: $a, b, c=50 \mu \mathrm{m} ; \mathrm{d}=10 \mu \mathrm{m}$. 
in ethanol and embedded in an Epon/Araldite mixture; the ultrathin sections were then stained with uranyl acetate and lead citrate.

For immunoelectron microscopy, the ELS tissue was fixed with a mixture of $0.5 \%$ glutaraldehyde and $2 \%$ paraformadldehyde for 2 $\mathrm{hr}$ at $4^{\circ} \mathrm{C}$, dehydrated in ethanol, and then embedded in LR White (London Resin; Basingstoke, UK). Ultrathin sections were labeled with the double-immunogold labeling method (Tanaka et al., 1997). Briefly, two faces of the grids were incubated with different antibodies (rabbit anti-V-ATPase E-subunit, 1:4000; guinea pig anti-otoconin-22, 1:4000) and then with goat anti-rabbit Ig or goat anti-guinea pig IgG conjugated with different sizes of gold particles (10 and 5 $\mathrm{nm}$, respectively) (BioCell; Cardiff, UK). The immunolabeled sections were fixed with $1 \%$ osmium tetroxide, stained with a mixture of uranyl acetate and methyl cellulose according to a published protocol (Roth et al., 1990), and then examined in a Hitachi 7500 electron microscope at $80 \mathrm{kV}$.

\section{RESULTS}

\section{Cloning of A- and E-subunits of V-ATPase}

We amplified each fragment from the bullfrog PVLS by the first PCR using primers 1 and 2 and obtained 566-bp and 299-bp fragments as candidates for the putative bullfrog A- and E-subunits, respectively. The amino acid sequences deduced from these fragments were homologous to the Xenopus A- and E-subunits of V-ATPase (AAH44025 and
AAH54191). We used these cDNA fragments as A- and Esubunit probes for screening of the cDNA library. From the screening of $6 \times 10^{4}$ plaques, two positive clones for the Asubunit and three for the E-subunit were identified, isolated, and sequenced. All of these clones had open reading frames (ORF).

Fig. 1 shows the full cDNA sequence of the A-subunit of $\mathrm{V}$-ATPase and the deduced amino acid sequence. The cDNA consisted of a 4-bp 5'-untranslated region and a 228bp 3'-UTR followed by a poly (A) tail. An ORF of 1,854 bp encoded a protein of 617 amino acids with a molecular mass calculated to be $68,168 \mathrm{Da}$. The bullfrog A-subunit showed the highest amino acid sequence similarity to the Xenopus laevis V-ATPase A-subunit (94\%; AAH44025), followed by a high similarity to the rat (88\%; XP-340988), mouse (88\%; Laitala-Leinonen et al., 1996), human (88\%; van Hille et al. 1993), pig (87\%; Sander et al. 1992), and killifish A-subunits (87\%; Katoh et al., 2003).

Fig. 2 shows the full cDNA sequence of the E-subunit of V-ATPase and the deduced amino acid sequence. This cDNA comprised a 58-bp 5'-UTR and a 781-bp 3'-UTR followed by a poly (A) tail. A 681-bp ORF encoded a protein of 226 amino acids with a molecular mass calculated to be 26,020 Da. The bullfrog E-subunit showed a high similarity
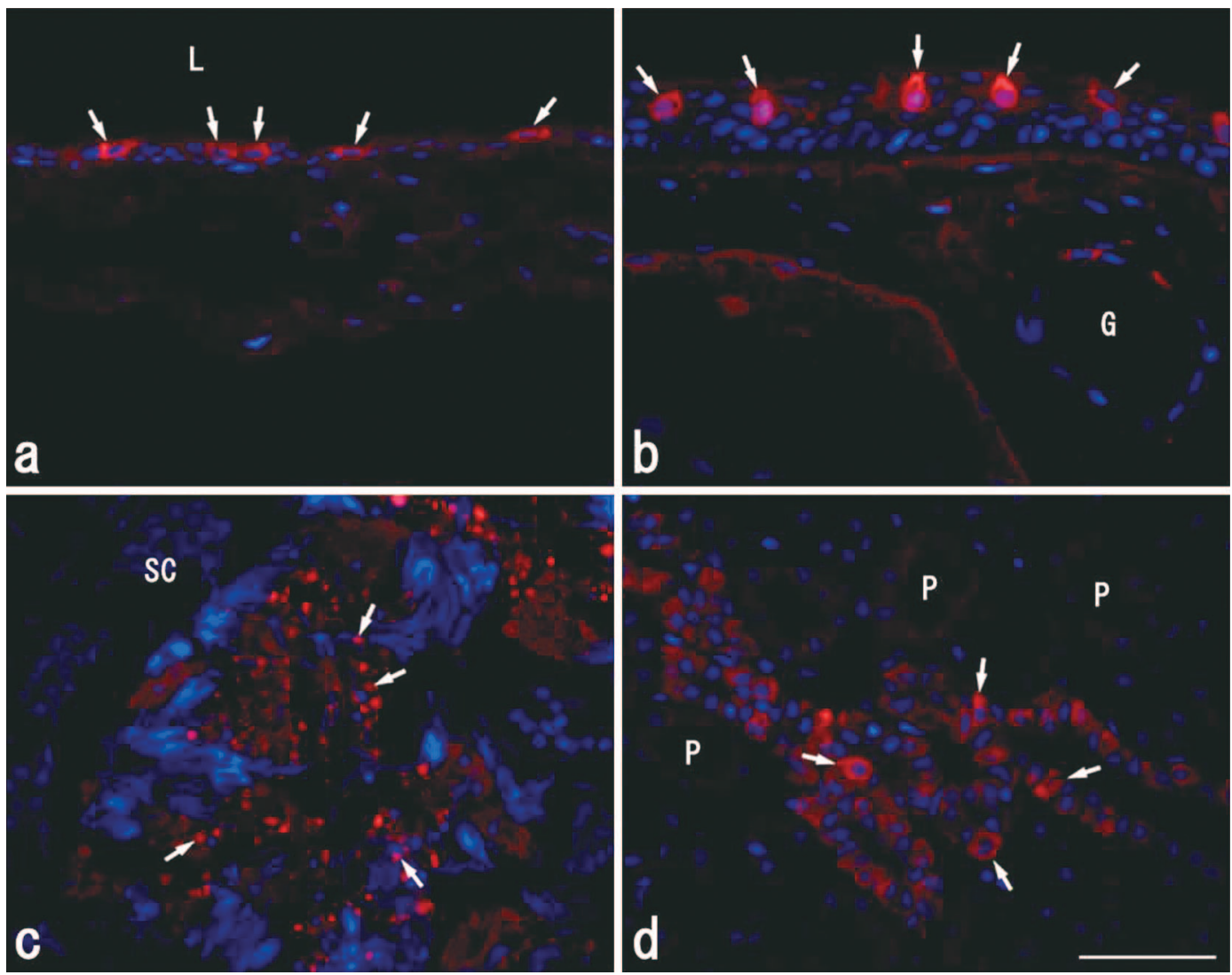

Fig. 5. Immunofluorescence localization of the V-ATPase E-subunit in the urinary bladder, ventral skin, testis, and kidney. (a) V-ATPaseexpressing cells (arrows) are regularly arranged in the epithelium of the urinary bladder. (b) In the ventral skin, flask-shaped V-ATPaseexpressing cells (arrows) are clearly visible among the granular cells. (c) A very limited positive reaction (arrows) is evident in the region of the nucleus in the spermatids, but not in the spermatocytes (SC). (d) In the kidney, labels for V-ATPase (arrows) are detected in the cytoplasm of intercalated cells, but not in other regions, including the collected duct. Arrows, positive reaction; L, lumen; G, exocrine gland; P, proximal tubules. Bar $=50 \mu \mathrm{m}$. 
to the Xenopus laevis (87\%; AAH54191), cattle (84\%; Hirsch et al., 1988), mouse (84\%; Laitala-Leinonen et al., 1996), human (84\%; Hemken et al., 1992), chicken (84\%; CAG31744), and zebrafish V-ATPase E-subunits $(82 \%$; AAH34666). These full-length cDNAs sequences have been deposited in the DDBJ/EMBL/GenBank database (accession nos. AB250091 and AB250092).

\section{Specificity of antisera}

To test the specificity of the antiserum toward the bullfrog ELS, we performed Western blot analysis of protein extracts of ELS, urinary bladder, ventral skin, testis, and kidney. The antiserum against the E-subunit of V-ATPase detected two bands in the extract of the ELS: a major band at $32.8 \mathrm{kDa}$ and a minor one at $25.4 \mathrm{kDa}$ (Fig. 3a, lane 1).
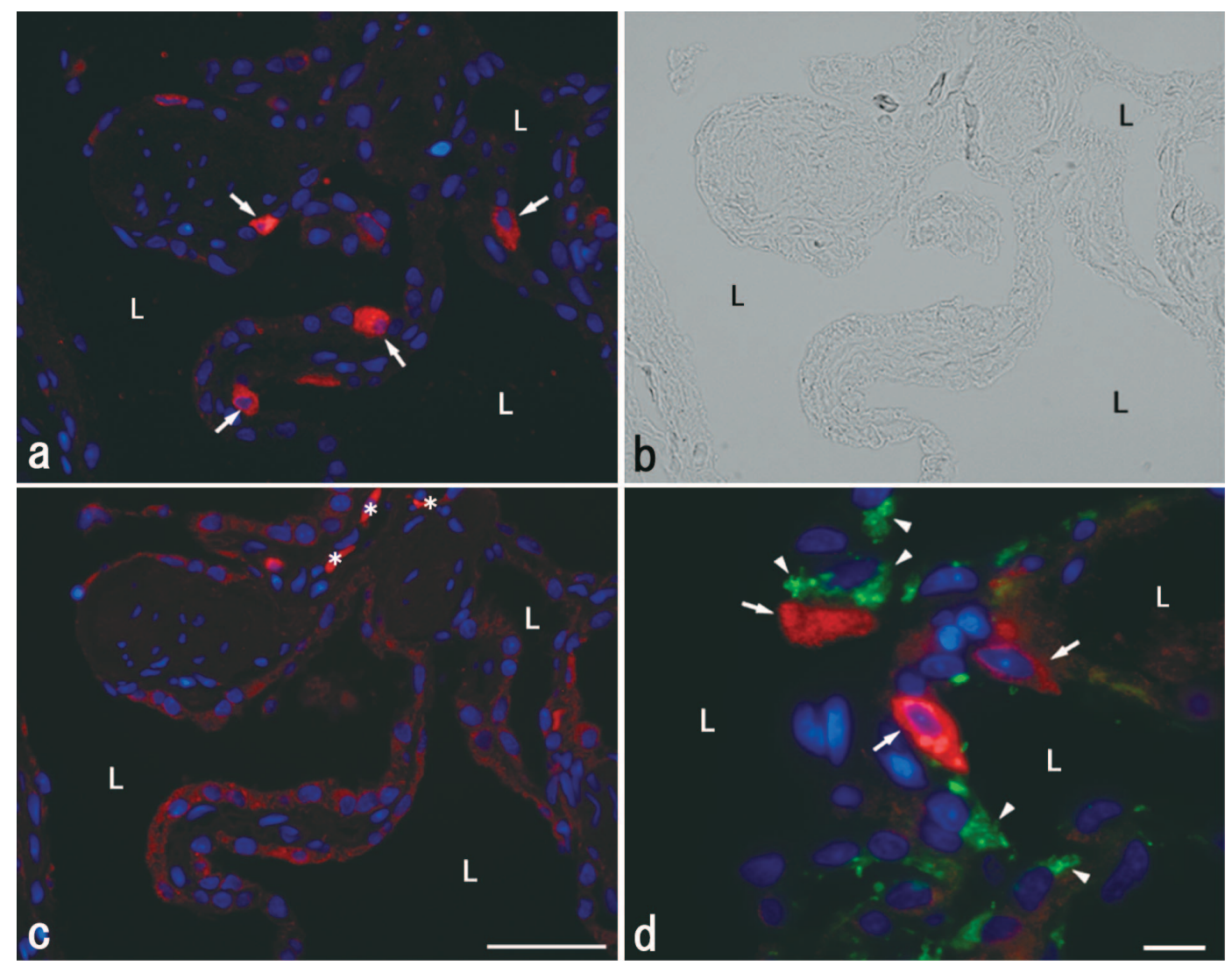

Fig. 6. Immunofluorescence localization of the V-ATPase A-subunit in the endolymphatic sac. A fluorescence image for V-ATPase (a) and the corresponding Nomarski differential-interference constrast image (b) are shown. The labels (red; arrows) are seen in the cytoplasm of special cells in the follicular epithelium, similar to the case with the antibody against the V-ATPase E-subunit. (c) No labeling is detected in any of the cells of the endolymphatic sac when the anti-V-ATPase A-subunit is preabsorbed with the corresponding antigen peptide. (d) In this double-labeling image, V-ATPase-expressing cells (red; arrows) are observed among otoconin-22-producing cells (green; arrowheads). Nuclei are counterstained with DAPI (blue). Asterisks, red blood cells; L, lumen. Bars: $a, b, c=50 \mu \mathrm{m} ; \mathrm{d}=10 \mu \mathrm{m}$.
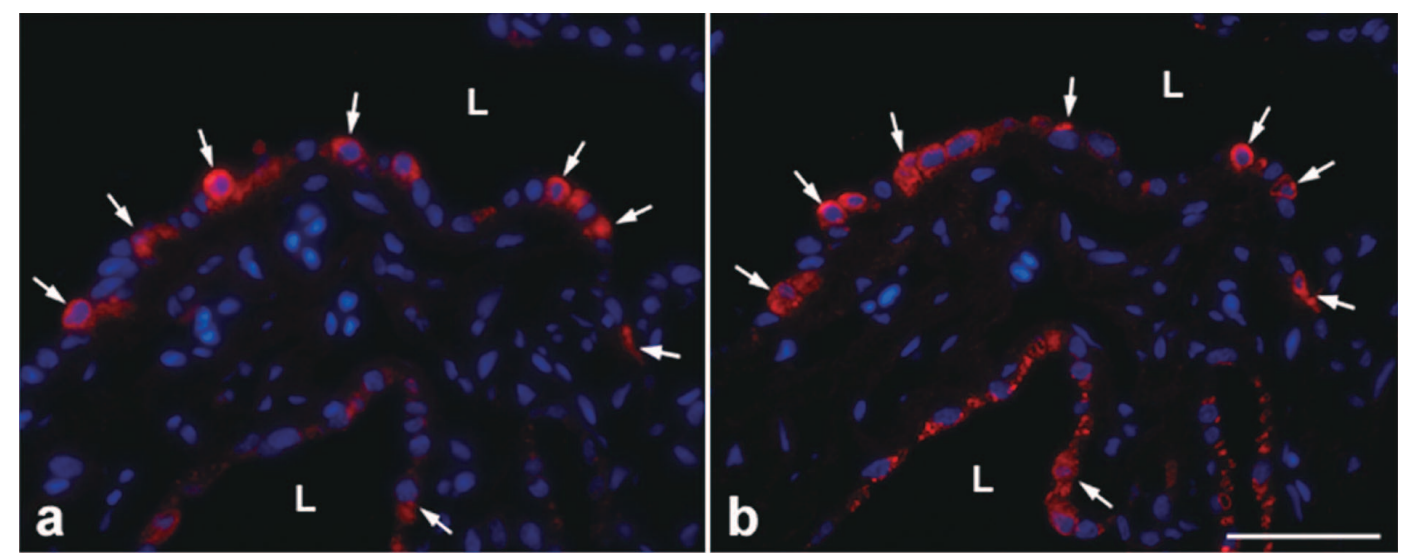

Fig. 7. Colocalization of the V-ATPase A-subunit (a) and E-subunit (b) in the same cells (red; arrows) of the endolymphatic sac. Nuclei are counterstained with DAPI (blue). L, lumen. Bar=50 $\mu \mathrm{m}$. 

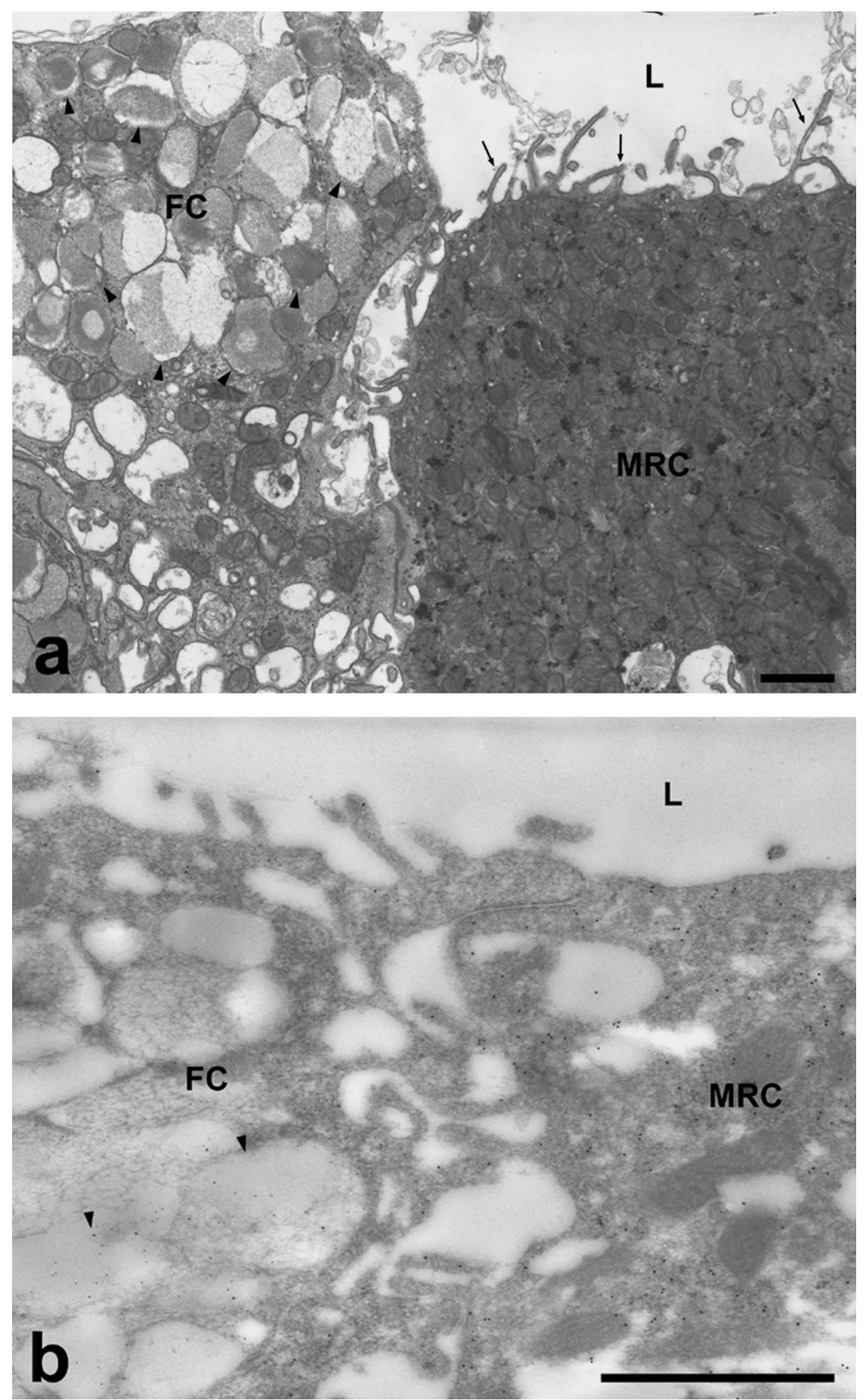

Fig. 8. (a) A transmission electron micrograph showing a mitochondria-rich cell (MRC) and a follicular cell (FC) bearing secretory granules (arrowheads) in the endolymphatic sac. In the mitochondria-rich cell, the cytoplasm is filled with mitochondria, and microvilli-like structures (arrows) are seen in the apical region of the cell membrane. (b) An electron micrograph showing the endolymphatic sac immunolabeled for $V$ ATPase and otoconin-22. Large particles indicating the presence of V-ATPase are visible in both the apical plasma membrane and cytoplasm in the mitochondria-rich cell (MRC), whereas small particles indicating the presence of otoconin-22 are detected in secretory granules (arrowheads) in the follicular cell (FC) of the sac. Bars $=1 \mu \mathrm{m}$. 
These bands were not detected when the anti-E-subunit was preabsorbed with the peptide used as the immunogen (Fig. 3b). When extracts of bullfrog urinary bladder, ventral skin, testis, and kidney were examined, the anti-E-subunit revealed only one band, at $32.8 \mathrm{kDa}$, in the urinary bladder, ventral skin, and kidney (Fig. 3a, lanes 2, 3 and 5), but two bands, a major (25.4 kDa) and a minor (32.8 kDa) one, in the testis (Fig. 3a, lane 4). When Western blot analysis was performed using anti-A-subunit, however, no positive bands were seen for any of these molecular masses, although a positive reaction was obtained when the immuofluorescence technique was used (see following section).

\section{Immunolocalization of $\mathbf{V}-\mathrm{H}^{+}$-ATPase}

The bullfrog ELS consists of follicular structures. The basic unit of this follicular structure comprises a monolayer of cuboidal epithelial cells, with the basal side comprising a thin layer of connective tissue and blood vessels. Immunolabeling for the E-subunit of V-ATPase was observed in the ELS (Fig. 4a, b). In the absorption test, the immunopositive reaction obtained with the antiserum was completely eliminated when $10 \mu \mathrm{g} / \mathrm{ml}$ of the antigen peptide was used as an adsorbent (Fig. 4c). When sections were double-immunolabeled with anti-E-subunit and anti-otoconin-22, the antisera labeled different cells (Fig. 4d). Examination of the urinary bladder, ventral skin, kidneys, and testes revealed that the V-ATPase E-subunit was present in all of these tissues, although the distribution pattern varied (Fig. 5). In the urinary bladder, positive labels for the V-ATPase E-subunit were distributed sparsely throughout the single epithelium (Fig. 5a), whereas in the ventral skin, these were visible in the flask-like shaped cells scattered between granular cells (Fig. 5b). The entire cytoplasm of these cells was uniformly immunolabeled. In the testes, apical portions, probably acrosomes, of the metamorphosing spermatids were labeled for the E-subunit (Fig. 5c), and in the kidneys the label was observed in specific cells of the connecting tubule and collecting tubules (Fig. 5d).

Similar patterns of labeling, especially in the ELS, were observed with the antiserum against the bullfrog V-ATPase A-subunit (Fig. 6a, b) and the labeling was eliminated after the antigen absorption test (Fig. 6c). When sections were double-immunolabeled with anti-A-subunit and anti-otoconin-22, positive reactions were found in separate cells (Fig. $6 \mathrm{~d})$. In addition, the V-ATPase E- and A-subunits were colocalized in the same cells of the ELS (Fig. 7).

\section{Immunoelectron microscopic observations}

Electron microcopy revealed that the epithelial cells in the ELS are of two cell types: one is characterized by having secretory granules and the other by having numerous mitochondria (Fig. 8a). When the ultrathin sections were doubleimmunolabeled for the E-subunit and otoconin-22, large immunogold particles for the E-subunit were observed exclusively in the apical region of plasma membrane and cytoplasm in the MR cells; small particles for otoconin-22 were detectable in the secretory granules in the follicular cells (Fig. 8b).

\section{DISCUSSION}

The present study demonstrates that MR cells contain- ing V-ATPase are located in the follicular epithelium of the bullfrog ELS. Previously, anti-mammalian V-ATPase subunits were used to identify cells containing V-ATPase in amphibians (Klein et al., 1997). Reports on the molecular identity of amphibian V-ATPase were cited in the database only for Xenopus laevis. Consequently, we cloned cDNAs encoding the A- and E-subunits of bullfrog V-ATPase and generated specific antibodies against them. The A-subunit is one of eight subunits found in the cytosolic $\mathrm{V}_{1}$; it is arranged in an alternating manner in a pseudo-hexagonal head-piece (Gruber et al., 2001) and has been suggested to be the nucleotide binding site (Feng and Forgac, 1992). The $\mathrm{V}_{1} \mathrm{E}$ subunit is essential for the assembly and activity of $V$ ATPase, as has been observed in yeast (Foury, 1990; Ho et al., 1993). The cDNA and deduced amino acid sequences of the V-ATPase A- and E-subunits determined in the present study have a high degree of identity with those of $V$ ATPase from other species.

In our Western blot analysis, the antiserum against the E-subunit recognized two specific proteins in the ELS with molecular masses at approximately 25.4 and $32.8 \mathrm{kDa}$. The $25.4-\mathrm{kDa}$ band was in agreement with the expected size (26.0 kDa) of the E-subunit of bullfrog V-ATPase. Because both bands were completely eliminated by preincubating antiserum with the respective immunizing peptide, they can be considered to be specific for the E-subunit. The E-subunit was ubiquitously expressed in several of the tissues examined in this study. However, we found two proteins with different molecular masses in the Western blotting analysis, and the degree of their expression appeared to be tissuespecific.

The B-subunit of V-ATPase is commonly found as two isoforms in mammals (Nelson et al., 1992). The B1 isoform is expressed in intercalated cells of the renal collecting duct. In contrast, the B2 isoform is ubiquitously expressed and has a predominant cytoplasmic localization in most intercalated cells of the kidney (Paunescu et al., 2004). E-subunit isoforms have also been found in the acrosome of spermatids during mouse spermiogenesis (Sun-Wada et al., 2002). Thus, it will be interesting to elucidate whether the differential expression of these two proteins reflects tissue-specific expression of the V-ATPase E-subunit in bullfrogs.

We were unable to detect any bands for the V-ATPase A-subunit in the Western blot analysis. However, positive reactions were obtained by immuofluorescence with the same antiserum and were abolished when the corresponding antigen peptide was used for adsorption. Consequently, this antiserum was conceivably specific for the V-ATPase Asubunit, and the cause of this result remains unknown at present.

Our immuofluorescence results demonstrated that $\mathrm{V}$ ATPase is expressed in specific cells of the bullfrog ELS, urinary bladder, ventral skin, testes, and kidneys. In addition, the immunoelectron microscopy experiment revealed that the follicular cells containing V-ATPase in the ELS are MR cells. These findings bring to mind the known functions of MR cells in the skin and urinary bladder of amphibians (Brown and Breton, 1996; Wieczorek et al., 1999). Much attention has been paid to the MR cells of amphibian skin because they provide a useful model for studying ion-transporting mechanisms. The MR cells of amphibian skin con- 
tain carbonic anhydrase II, which catalyzes the dehydration of $\mathrm{CO}_{2}$ to produce $\mathrm{H}^{+}$and $\mathrm{HCO}_{3}^{-}$(Rosen and Friedley, 1973; Katz and Gabbay, 1988). $\mathrm{HCO}_{3}{ }^{-}$is secreted across the skin surface via a $\mathrm{Cl}^{-} / \mathrm{HCO}_{3}^{-}$anion exchanger (band 3) (Jensen et al., 1997). In support of this model, a band 3-like anion exchanger has been shown to be present in MR cells of Bufo viridis (Devuyst et al., 1993). $\mathrm{H}^{+}$, which is transported from the MR cells to the skin surface by V-ATPase, is considered to facilitate $\mathrm{Na}^{+}$absorption (Ehrenfeld et al., 1985; 1989).

In mammals, MR cells are present in the kidney, epididymis, vas deferens, testis, and inner ear. V-ATPase is highly expressed in MR cells in the kidney (Brown et al., 1988; Wagner et al., 2004), epididymis, and vas deferens (Brown et al., 1992), where they play a major role in the acidification of urine and the luminal fluid of the reproductive tract (Breton et al., 1996; Brown et al., 1997; Brown and Breton, 2000; Gluck et al., 1982). In addition, V-ATPase is expressed in the acrosome of developing spermatids and in mature sperm in mouse testes, suggesting a role in processing the protease zymogen essential for fertilization (SunWada et al., 2002). V-ATPase-positive MR cells in the mammalian inner ear are considered to be responsible for the adjustment of $\mathrm{pH}$ in the lymph (Stankovic et al., 1997). In the mammalian ELS, the presence of MR cells has also been shown by electron microscopy (Peter et al., 2002). The VATPase-expressing cells detected by the present immunofluoresecence study may have functions similar to those mentioned above.

In the mammalian kidney, two subtypes of intercalated cell are present, the A- and B-types, which are involved in $\mathrm{H}^{+}$and bicarbonate secretion, respectively. V-ATPase is located in the apical plasma membrane of the A-cells and in the basolateral membrane of the B-cells. Furthermore, $\mathrm{Cl}^{-} /$ $\mathrm{HCO}_{3}{ }^{-}$anion exchange has been localized to the basolateral membrane of the A-cells and to the apical membrane of the B-cells (Brown and Breton, 1996, 2000). The carbonic anhydrase II in these intercalated cells catalyzes the dehydration of $\mathrm{CO}_{2}$ to produce $\mathrm{H}^{+}$and $\mathrm{HCO}_{3}{ }^{-}$. Based on analogy with the intercalated cells in mammalian kidneys, the MR cells in the bullfrog ELS may be equivalent to intercalated Acells and, at least partially, responsible for the proton secretion that reduces luminal $\mathrm{pH}$ in this tissue, thereby dissolving the crystals. In the present study, however, a positive reaction for V-ATPase was observed throughout the entire cytoplasm of almost all of the cells examined, and we were not able to obtain clear evidence showing the location of $\mathrm{V}$ ATPase in the apical plasma membrane. Paunescu et al. (2004) showed that in response to chronic carbonic anhydrase inhibition by acetazolamide, the B2 isoform of $\mathrm{V}$ ATPase changes localization from the cytoplasm to the apical membrane in the A-cells among the intercalated cells. Consequently, it may be possible that the A- or E-subunits of bullfrog V-ATPase redistribute from the cytoplasm to the apical plasma membrane under certain physiological conditions. Further studies on the activation of proton secretion in the ELS will be necessary to address this possibility.

Taken together, this study provides new evidence suggesting the presence of V-ATPase, including the A- and Esubunits, in MR cells of the bullfrog ELS as well as of the skin and urinary bladder. The V-ATPase in MR cells of the
ELS might be involved in the dissolution of the calcium carbonate crystals found in the lumen of the ELS.

\section{ACKNOWLEDGMENTS}

This investigation was supported in part by a grant-in-aid for scientific research from the Ministry of Education, Science, Sports, and Culture of Japan to ST.

\section{REFERENCES}

Breton S, Smith PJ, Lui B, Brown D (1996) Acidification of the male reproductive tract by a proton pumping $\mathrm{H}^{+}$-ATPase. Nat Med 2: 470-472

Brown D, Hirsch S, Gluck S (1988) An $\mathrm{H}^{+}$-ATPase in opposite plasma membrane domains in kidney epithelial cell subpopulations. Nature 331: 622-624

Brown D, Lui B, Gluck S, Sabolic I (1992) A plasma membrane proton ATPase in specialized cells of rat epididymis. Am J Physiol 263: C913-916

Brown D, Breton S (1996) Mitochondria-rich, proton-secreting epithelial cells. J Exp Biol 199: 2345-2358

Brown D, Smith PJ, Breton S (1997) Role of V-ATPase-rich cells in acidification of the male reproductive tract. J Exp Biol 200: 257262

Brown D, Breton S (2000) $\mathrm{H}^{+} \mathrm{V}$-ATPase-dependent luminal acidification in the kidney collecting duct and the epididymis/vas deferens: vesicle recycling and transcytotic pathways. J Exp Biol 203: $137-145$

Devuyst O, Rott R, Denef JF, Crabbe J, Katz U (1993) Localization of a band 3-related protein in the mitochondria-rich cells of amphibian skin epithelium. Biol Cell 78: 217-221

Ehrenfeld J, Garcia-Romeu F, Harvey BJ (1985) Electrogenic active proton pump in Rana esculenta skin and its role in sodium ion transport. J Physiol (Lond) 359: 331-355

Ehrenfeld J, Lacoste I, Harvey BJ (1989) The key role of the mitochondria-rich cell in $\mathrm{Na}+$ and $\mathrm{H}+$ transport across the frog skin epithelium. Pflugers Arch 414: 59-67

Feng Y, Forgac M (1992) Cysteine 254 of the 73-kDa A subunit is responsible for inhibition of the coated vesicle $\mathrm{H}^{+}$-ATPase upon modification by sulfhydryl reagents. J Biol Chem 267: 58175822

Forgac M (1999) Structure and properties of the vacuolar $\mathrm{H}^{+}-$ ATPases. J Biol Chem 274: 12951-12954

Foury F (1990) The 31-kDa polypeptide is an essential subunit of the vacuolar ATPase in Saccharomyces cerevisiae. J Biol Chem 265: 18554-18560

Futai M, Oka T, Sun-Wada G, Moriyama Y, Kanazawa H, Wada $Y$ (2000) Luminal acidification of diverse organelles by V-ATPase in animal cells. J Exp Biol 203: 107-116

Gluck S, Cannon C, Al-Awqati Q (1982) Exocytosis regulates urinary acidification in turtle bladder by rapid insertion of $\mathrm{H}^{+}$ pumps into the luminal membrane. Proc Natl Acad Sci USA 79: 4327-4331

Gruber G, Wieczorek H, Harvey WR, Muller V (2001) Structurefunction relationships of A-, F- and V-ATPases. J Exp Biol 204: 2597-2605

Hemken P, Guo XL, Wang ZQ, Zhang K, Gluck S (1992) Immunologic evidence that vacuolar $\mathrm{H}^{+}$ATPases with heterogeneous forms of $\mathrm{Mr}=31,000$ subunit have different membrane distributions in mammalian kidney. J Biol Chem 267: 9948-9957

Hirsch S, Strauss A, Masood K, Lee S, Sukhatme V, Gluck S (1988) Isolation and sequence of a cDNA clone encoding the $31-\mathrm{kDa}$ subunit of bovine kidney vacuolar $\mathrm{H}^{+}$-ATPase. Proc Natl Acad Sci USA 85: 3004-3008

Ho MN, Hill KJ, Lindorfer MA, Stevens TH (1993) Isolation of vacuolar membrane $\mathrm{H}^{+}$-ATPase-deficient yeast mutants; the VMA5 and VMA4 genes are essential for assembly and activity of the 
vacuolar $\mathrm{H}^{+}$-ATPase. J Biol Chem 268: 221-227

Jensen LJ, Sorensen JN, Larsen EH, Willumsen NJ (1997) Proton pump activity of mitochondria-rich cells. The interpretation of external proton-concentration gradients. J Gen Physiol 109: 73-91

Katoh F, Hyodo S, Kaneko T (2003) Vacuolar-type proton pump in the basolateral plasma membrane energizes ion uptake in branchial mitochondria-rich cells of killifish Fundulus heteroclitus, adapted to a low ion environment. J Exp Biol 206: 793-803

Katz U, Gabbay S (1988) Mitochondria-rich cells and carbonic anhydrase content of toad skin epithelium. Cell Tissue Res 251: 425-431

Klein U, Timme M, Zeiske W, Ehrenfeld J (1997) The $\mathrm{H}^{+}$pump in frog skin (Rana esculenta): identification and localization of a $\mathrm{V}$ ATPase. J Membr Biol 157: 117-126

Laitala-Leinonen T, Howell ML, Dean GE, Vaananen HK (1996) Resorption-cycle-dependent polarization of mRNAs for different subunits of V-ATPase in bone-resorbing osteoclasts. Mol Biol Cell 7: $129-142$

Nelson RD, Guo XL, Masood K, Brown D, Kalkbrenner M, Gluck S (1992) Selectively amplified expression of an isoform of the vacuolar $\mathrm{H}^{+}$-ATPase 56-kilodalton subunit in renal intercalated cells. Proc Natl Acad Sci USA 89: 3541-3545

Nelson N, Harvey WR (1999) Vacuolar and plasma membrane proton-adenosinetriphosphatases. Physiol Rev 79: 361-385

Nishi T, Forgac M (2002) The vacuolar $\mathrm{H}^{+}$-ATPases-nature's most versatile proton pumps. Nat Rev Mol Cell Biol 3: 94-103

Paunescu TG, Da Silva N, Marshansky V, McKee M, Breton S, Brown D (2004) Expression of the 56-kDa B2 subunit isoform of the vacuolar $\mathrm{H}^{+}$-ATPase in proton-secreting cells of the kidney and epididymis. Am J Physiol Cell Physiol 287: C149-162.

Peters TA, Tonnaer EL, Kuijpers W, Cremers CW, Curfs JH (2002) Differences in endolymphatic sac mitochondria-rich cells indicate specific functions. Laryngoscope 112: 534-541

Pote KG, Hauer CRI, Michel H, Shabanowitz J, Hunt DF, Kretsinger $\mathrm{RH}$ (1993) Otoconin-22, the major protein of aragonitic frog otoconia, is a homolog of phospholipase $A_{2}$. Biochemistry 32 : 5017-5024

Rosen S, Friedley NJ (1973) Carbonic anhydrase activity in Rana pipiens skin: biochemical and histochemical analysis. Histochemie 36: 1-4
Roth J, Taatjes DJ, Tokuyasu KT (1990) Contrasting of Lowicryl K4M thin sections. Histochemistry 95:123-136

Sander I, Lottspeich F, Appelhans H, Kojro E, Spangenberg J, Weindel C, Haase W, Koepsell H (1992) Sequence analysis of the catalytic subunit of $\mathrm{H}^{+}$-ATPase from porcine renal brushborder membranes. Biochim Biophys Acta 1112: 129-141

Stankovic KM, Brown D, Alper SL, Adams JC (1997) Localization of $\mathrm{pH}$ regulating proteins $\mathrm{H}^{+}$ATPase and $\mathrm{Cl}^{-} / \mathrm{HCO}_{3}{ }^{-}$exchanger in the guinea pig inner ear. Hear Res 114: 21-34

Sun-Wada GH, Imai-Senga Y, Yamamoto A, Murata Y, Hirata T, Wada Y, Futai M (2002) A proton pump ATPase with testis-specific $\mathrm{E} 1$-subunit isoform required for acrosome acidification. $J$ Biol Chem 277: 18098-18105

Tanaka S, Kurosumi K (1992) A certain step of proteolytic processing of proopiomelanocortin occurs during the transition between two distinct stages of secretory granules maturation in rat anterior pituitary corticotrophs. Endocrinology 131: 779-786

Tanaka S, Yora T, Nakayama K, Inoue K, Kurosumi K (1997) Proteolytic processing of pro-opiomelanocortin occurs in acidifying secretory granules of AtT-20 cells. J Histochem Cytochem 45: 425-436

van Hille B, Richener H, Evans DB, Green JR, Bilbe G (1993) Identification of two subunit $A$ isoforms of the vacuolar $\mathrm{H}^{+}$-ATPase in human osteoclastoma. J Biol Chem 268: 7075-7080

Wagner CA, Finberg KE, Breton S, Marshansky V, Brown D, Geibel JP (2004) Renal vacuolar $\mathrm{H}^{+}$-ATPase. Physiol Rev 84: 12631314

Wieczorek H, Brown D, Grinstein S, Ehrenfeld J, Harvey WR (1999) Animal plasma membrane energization by proton-motive $\mathrm{V}$ ATPases. Bioessays 21: 637-648

Yaoi Y, Kikuyama S, Hayashi H, Hanaoka Y, Sakai M, Tanaka S (2001) Immunocytochemical localization of secretory phospholipase $\mathrm{A}_{2}$-like protein in the pituitary gland and surrounding tissue of the bullfrog, Rana catesbeiana. J Histochem Cytochem 49: $631-637$

Yaoi Y, Suzuki M, Tomura H, Sasayama Y, Kikuyama S, Tanaka S (2003) Molecular cloning of otoconin-22 cDNA in the bullfrog endolymphatic sac: effect of calcitonin on the otoconin-22 mRNA levels. Endocrinology 144: 3287-3296

(Received August 26, 2006 / Accepted September 30, 2006) 